\title{
Pengaruh Cekaman Suhu Tinggi pada Fase Bibit terhadap Pertumbuhan dan Hasil Umbi Dua Varietas Tanaman Kentang (Solanum Tuberosum L.)
}

\author{
Effect of High Temperature Stress on The Growth and Yield of Two Potato Varieties at \\ Seedling Stage (Solanum Tuberosum L.)
}

\author{
Author(s): Riani Ningsih ${ }^{(1)^{*}}$; Slameto ${ }^{(1)}$; Ketut Anom Wijaya ${ }^{(1)}$ \\ (1) Fakultas Pertanian, Universitas Jember \\ * Corresponding author: riani_ningsih@polije.ac.id
}

Submitted: 11 Nov $2020 \quad$ Accepted: 25 Aug $2021 \quad$ Published: 30 Sep 2021

\begin{abstract}
ABSTRAK
Kentang umumnya dapat tumbuh optimal di dataran tinggi, ketika kentang ditanam di dataran medium maka pertumbuhan tanaman akan terganggu. Hal ini dikarenakan pada dataran medium memiliki suhu yang relative tinggi. Oleh karena itu perlu dilakukan penelitian untuk mengetahui respon tanaman kentang jika ditanam pada suhu tinggi. Penelitian ini bertujuan untuk mengetahui pengaruh cekaman suhu tinggi pada fase bibit terhadap pertumbuhan dan hasil pada tanaman kentang yang dilaksanakan di Jember dengan ketinggian di atas $500 \mathrm{mdpl}$ (suhu rerata $32^{\circ} \mathrm{C}$ ). Penelitian ini dilaksanakan dengan menggunakan rancangan acak kelompok (RAK) faktorial yang terdiri dari dua faktor yaitu faktor pertama perlakuan suhu yaitu, Suhu Kontrol $32^{\circ} \mathrm{C}$ (T0), Suhu $25^{\circ} \mathrm{C} 16$ jam dan $35^{\circ} \mathrm{C}, 8$ jam selama 15 hari $(\mathrm{T} 1)$, Suhu $42^{\circ} \mathrm{C}$ selama 8 jam (T2). Faktor kedua perlakuan varietas yaitu, varietas atlantik (V1), dan varietas granola (V2). Sehingga terdapat 6 kombinasi perlakuan dengan ulangan 4 kali. Data dianalisis menggunakan uji lanjut jarak berganda duncan 5\%. Hasil penelitian interaksi antara perlakuan cekaman suhu kontrol $32^{\circ} \mathrm{C}$ dan varietas granola kembang menunjukkan hasil terbaik pada variabel pengamatan tinggi tanaman sebesar $36,31 \mathrm{~cm}$, jumlah daun sebanyak 15,95 helai, dan kandungan karbohidrat sebesar 22,49 mg/g. Sedangkan interaksi antara perlakuan cekaman suhu kontrol $32^{\circ} \mathrm{C}$ dan varietas atlantik menunjukkan hasil terbaik pada variabel pengamatan berat umbi sebesar 17,4 g.
\end{abstract}

\section{Kata Kunci:}

Kentang,

Suhu Tinggi,

Senyawa Kimia

\section{Keywords:}

Potatoes,

High

Temperature,

Chemical

Compounds

\section{ABSTRACT}

Potatoes can be optimally grown on highlands, when potatoes are planted in medium plains, the plant growth will be disturbed. This is due to the medium plains which have relatively high temperatures. Therefore it is necessary to conduct some research to observe the crop's responses affected by high temperatures. The research objective is to see the effect of high temperature stress on growth and yield in two potato varieties. There search field is located in Jember City-East Java Province (altitude 500m, mean temperature 320C. The experiment used Randomized Block Design (RBD) within two factors, the first factor was temperature grouped as Control Temperature (T0), Temperature $25^{\circ} \mathrm{C}-35^{\circ} \mathrm{C}$ for 15 days, and Temperature $42^{\circ} \mathrm{C}$ for 8 hours (T2). The secondary factor was variety using two potatoes variety namely Atlantik (V1) and Granola (V2). Consequently, the experiment had 6 combinations of treatment with four replications each. The analysis used Duncan's multiple continue test 5\%. The results of the interaction study between the $320 \mathrm{C}$ control temperature stress treatment and the granola kembang plant varieties showed the best results on the observation variable of plant height of $36.31 \mathrm{~cm}$, the number of leaves as much as 15.95 pieces, and carbohydrate content of 22.49 $\mathrm{mg} / \mathrm{g}$. Meanwhile, the interaction between temperature stress treatment of $32^{\circ} \mathrm{C}$ control and Atlantic varieties showed the best results on the tuber weight observation variable of $17.4 \mathrm{~g}$. 


\section{PENDAHULUAN}

Kentang (Solanum tuberosum L.) merupakan salah satu umbi-umbian yang banyak di tanam di berbagai negara dan digunakan sebagai sumber karbohidrat dengan memanfaatkan umbinya menjadi produk pangan maupun non pangan. Kentang dimanfaatkan dalam pemenuhan gizi terutama mineral (fosfor, besi dan kalium) serta vitamin B1 (thiamin) dan vitamin C (Asgar, 2013). Hasil olahan kentang yang banyak berada di pasaran dunia umumnya berupa pati, tepung, kentang beku, kentang kering, keripik kentang dan kentang goreng (Diny, Handayani, \& Sofiari, 2017)

Produksi kentang nasional mengalami fluktuasi dari tahun 2013 hingga 2016. Produksi kentang nasional pada 2013 adalah 1.124.282 ton dan mengalami peningkatan jumlah produksi yaitu 1.347.815 ton pada 2014 kemudian mengalami penurunan hasil produksi sebesar 1.219.270 ton pada tahun 2015 dan mengalami penurunan jumlah produksi yaitu 1.213 .038 to pada tahun 2016 (Badan Pusat Statistik, 2017). Fluktuasi juga terjadi pada jumlah konsumsi kentang per kapita dalam setahun sejak 2012 hingga 2015 yaitu $1.460 \quad \mathrm{~kg} / \mathrm{kapita} 1, \quad 1.564$ $\mathrm{kg} / \mathrm{kapita}$ dan mengalami penurunan pada 2014 menjadi $1.460 \mathrm{~kg} / \mathrm{kapita}$ dan mengalami peningkatan cukup signifikan hingga $2.294 \mathrm{~kg} /$ kapita (Pusat Data dan Informasi, 2016).

Berbagai upaya intensifikasi telah banyak dilakukan, mulai dari penggunaan varietas unggul sampai dengan perbaikan teknik budidaya. Sebaliknya upaya ekstensifikasi dihadapkan pada kendala geografis terkait dengan karakteristik tanaman kentang yang membutuhkan suhu relatif rendah selama pertumbuhannya. Untuk membuka peluang ekstensifikasi pertanaman kentang serta mengurangi dampak negatif dan risiko yang mungkin terjadi akibat penanaman di dataran tinggi perlu dicari alternatif pengembangan tanaman di dataran medium dengan hasil dan kualitas hasil yang relatif sama dengan dataran tinggi.

Ketinggian tempat yang berbeda umumnya berhubungan dengan perbedaan suhu, terutaman suhu siang dan malam. Suhu pada kebanyakan dataran medium ini umumnya melebihi suhu optimal yang dibutuhkan tanaman kentang untuk tumbuh dan berproduksi dengan baik. (Enoch et al., 2018) menjelaskan bahwa daerah yang mempunyai suhu udara maksimum $30^{\circ} \mathrm{C}$ dan suhu udara minimum $15^{\circ} \mathrm{C}$ adalah daerah yang sangat baik untuk pertumbuhan tanaman kentang daripada daerah yang mempunyai suhu relatif konstan yaitu rata-rata $24^{\circ} \mathrm{C}$. Peningkatan suhu akibat penurunan ketinggian tempat dapat mengakibatkan tanaman mengalami cekaman suhu tinggi. Pada suhu tanah mencapai $30^{\circ} \mathrm{C}$ aktivitas beberapa enzim yang berperan dalam metabolisme pati tertekan sehingga terjadi penurunan kadar pati pada ubi (Syahbudin; Yuwariah, Y; Hamdani, 2013). Permasalahan utama dalam budidaya tanaman kentang adalah faktor lingkungan salah satunya adalah suhu, perbedaan suhu lingkungan yang signifikan akan mempengaruhi hasil produksi kentang.

Selain suhu dan lingkungan tempat tumbuh, varietas merupakan salah satu faktor penentu keberhasilan budidaya tanaman kentang di dataran medium. Berkaitan dengan karakteristik tanaman kentang yang membutuhkan suhu rendah selama pertumbuhannya, diperlukan varietas kentang yang relatif lebih adaptif terhadap suhu yang lebih tinggi pada dataran medium.

\section{METODOLOGI}

Penelitian ini dilaksanakan pada bulan Februari 2019 sampai Agustus 2019 di Rembangan, Kecamatan Arjasa, Kabupaten Jember dan Laboratorium 
Teknologi Benih Fakultas Pertanian Universitas Jember.

Penelitian ini dilaksanakan dengan menggunakan rancangan acak kelompok (RAK) faktorial yang terdiri dari dua faktor yaitu faktor pertama perlakuan suhu yaitu, Suhu Kontrol $32^{\circ} \mathrm{C}(\mathrm{T} 0)$, Suhu $25^{\circ} \mathrm{C}$ selama 16 jam dan $35^{\circ} \mathrm{C}$ selama 8 jam dalam kurun waktu 15 hari (T1), Suhu $42^{\circ} \mathrm{C}$ selama 8 jam (T2). Faktor kedua perlakuan varietas yaitu, varietas atlantik (V1), dan varietas granola (V2). Sehingga terdapat 6 kombinasi perlakuan dengan ulangan 4 kali. Data kemudian dianalisis menggunakan uji lanjut jarak berganda duncan $5 \%$

Bibit di peroleh dari umbi G0 yang telah dikecambahkan sehingga muncul tunas. Bibit yang sudah berumur 21 hari di perlakukan di growth chamber dengan perlakuan suhu. Hasil bibit yang di perlakukan di growth chamber selanjutnya di pindah ke dataran medium dengan ketinggian berkisar $500 \mathrm{mdpl}$. Penanaman bibit kentang dengan posisi tunas menghadap ke atas diantara pupuk pada garitan yang disiapkan. Pemupukan pada tanaman kentang di lakukan dua kali, yaitu pada pemupukan dasar dan pemupukan susulan. Penentuan umur panen tergantung varietas/kultivar (100 - 110 hari), cuaca/musim, dan pemeliharaan tanaman. Pencatatan mengenai jenis dan jumlah pupuk dilakukan untuk menunjang data penelitian.

Pengujian pertumbuhan, dan fisiologi kentang variabel pengamatan sebagai berikut:

\section{a. Tinggi Tanaman}

Tinggi tanaman diukur dari permukaan tanah sampai titik tumbuh tanaman. Pengukuran dilakukan pada umur 7 minggu setelah tanam (mst).

b. Jumlah Daun

Jumlah daun bertujuan untuk mengetahui seberapa banyak daun yang terbentuk selama fase pertumbuhan. Perhitungan jumlah daun dilakukan pada umur 7 minggu setelah tanam (mst).

c. Berat Umbi per Tanaman

$\begin{array}{ccc}\text { Umbi } & \text { dari } & \text { masing-masing } \\ \text { tanaman } & \text { sampel dikumpulkan, }\end{array}$ kemudian ditimbang setelah dibersihkan dari sisa-sisa tanah pada saat panen yaitu tanaman berumur 105 HST.

d. Karbohidrat umbi

Umbi yang digunakan adalah umbi hasil panen dari tanaman yang berumur 105 HST. Pengukuran kandungan karbohidrat ditentukan menggunakan Sadasivam and Manickam (2017). Sebanyak 3gram umbi kentang dihidrolisis dengan $5 \mathrm{ml}$ larutan 2,5 N HCl dan dipanaskan dalam waterbath selama 3 jam, setelah dingin dinetralisir dengan $\mathrm{Na}_{2} \mathrm{CO}_{3}$. Larutan sampel dimasukkan dalam labu ukur $100 \mathrm{ml}$ dan digenapkan dengan aquadest hingga garis tera lalu digojok selama 30 menit dengan kecepatan $3.000 \mathrm{rpm}$. 0,5 $\mathrm{ml}$ supernatant ditambah $2 \mathrm{ml}$ reagen Anthronem, lalu dipanaskan dalam waterbath selama 8 menit pada suhu $40^{\circ} \mathrm{C}$, setelah dingin dilakukan pengukuran absorbansi menggunakan spektrofotometer pada panjang gelombang $630 \mathrm{~nm}$.

\section{HASIL DAN PEMBAHASAN}

Berdasarkan penelitian yang telah dilakukan untuk mengetahui Pengaruh Cekaman Suhu Tinggi terhadap Pertumbuhan, Hasil dan Senyawa Biokimia Pada Dua Varietas Tanaman Kentang (S. Tuberosum L.) di dataran medium melalui pengukuran beberapa parameter pengamatan maka diperoleh data pengamatan yang kemudian dianalisa menggunakan analisa sidik ragam (ANOVA). 
Tabel 1. Rekapitulasi Sidik Ragam pada Variabel Pengamatan

Table 1. Reapitulation of Variance on Variable Observation

\begin{tabular}{lcc}
\hline \multirow{2}{*}{$\begin{array}{l}\text { Parameter Pengamatan } \\
\text { Observation Parameters }\end{array}$} & \multicolumn{3}{c}{ Nilai Kuadrat Tengah } \\
Middle Quadrant
\end{tabular}

Keterangan: $(\mathrm{T})=$ Suhu; $(\mathrm{V})=$ Varietas; $\left({ }^{*}\right)=$ Berbeda nyata; $(* *)=$ Berbeda sangat nyata $) ;(\mathrm{ns})=$ Berbeda tidak nyata

Note: $(T)=$ Temperature; $(V)=$ Varieties; $(*)=$ significant $;(* *)=$ the most significant $;(n s)=$ not significant

\section{Tinggi Tanaman}

Tabel 2. Pengaruh Cekaman Suhu Tinggi pada Dua Varietas Kentang terhadap Tinggi Tanaman

Table 2. Effect of High Temperature Stress on Two Potato Varieties to Plant Height

\begin{tabular}{lcc}
\hline & \multicolumn{2}{c}{$\begin{array}{c}\text { Tinggi Tanaman } \\
\text { Plant Height }\end{array}$} \\
\cline { 2 - 3 } Treatment & $\begin{array}{c}\text { Atlantik } \\
\text { Atlantik }\end{array}$ & $\begin{array}{l}\text { Granola } \\
\text { Granola }\end{array}$ \\
\hline $\begin{array}{l}\text { Suhu } 32^{\circ} \mathrm{C} \\
\text { Temperature } 32^{\circ} \mathrm{C}\end{array}$ & $34,23 \mathrm{Ab}$ & $36,31 \mathrm{Aa}$ \\
Suhu $25^{\circ} \mathrm{C} / 35^{\circ} \mathrm{C}$ & $23,05 \mathrm{Bb}$ & $27,97 \mathrm{Ba}$ \\
Temperature $25^{\circ} \mathrm{C} / 35^{\circ} \mathrm{C}$ & $15,86 \mathrm{Ca}$ & $16,56 \mathrm{Ca}$ \\
Suhu $42^{\circ} \mathrm{C}$ & & \\
Temperature $42^{\circ} \mathrm{C}$ & &
\end{tabular}

Keterangan: huruf kecil (Vertikal) dan huruf kapital (Horisontal). Angka yang diikuti huruf yang berbeda menunjukkan perbedaan yang nyata menurut uji DMRT taraf $5 \%$.

Note: lowercase (vertical) and capital letters (horizontal). Numbers followed by different letters show asignificant difference according to the 5\% DMRT test.

Hasil anova pada Tabel 1 menunjukkan bahwa interaksi antara perlakuan suhu dan varietas menunjukkan hasil berbeda nyata pada variabel tinggi tanaman.
Berdasarkan Tabel 2 Perlakuan interaksi suhu kontrol dengan varietas granola kembang (T0V2) menunjukkan hasil yang tertinggi sebesar $36,31 \mathrm{~cm}$ dibandingkan perlakuan lain. Berdasarkan 
tingginya, tanaman kentang dapat diklasifikasikan menjadi lima tingkatan dalam karakter UPOV (2004), yaitu sangat pendek $(<44,0 \mathrm{~cm})$, pendek $(44,1-49,9$ $\mathrm{cm})$, sedang $(50,0-54,9 \mathrm{~cm})$, tinggi $(55,0$ - 59,9 cm), dan sangat tinggi $(60,0 \mathrm{~cm})$. Penelitian yang dilakukan oleh Kusmana (2012) menyatakan bahwa untuk menguji beberapa varietas kentang yang tahan ditanam di dataran tinggi saat musim kering menghasilkan kesimpulan bahwa granola kembang justru menunjukkan daya tumbuh yang tinggi daripada atlantik dan klon lain. Hasil penelitian yang telah dilakukan di dataran menengah juga menunjukkan bahwa varietas yang lebih adaptif adalah granola kembang.
Perlakuan Suhu T0 $\left(32^{\circ} \mathrm{C}\right)$ menunjukkan hasil yang optimal karena tidak adanya perlakuan suhu apapun pada fase bibit sehingga tanaman dapat tumbuh secara normal dan optimal ketika dipindahkan ke lahan. Penggunaan perlakuan suhu $25^{\circ} \mathrm{C} / 35^{\circ} \mathrm{C}$ selama 15 hari dan suhu $42^{\circ} \mathrm{C}$ selama 8 jam menunjukkan hasil yang kurang optimal pada tinggi tanaman kentang. Pengaruh cekaman suhu tinggi juga tergantung pada fase pertumbuhan tanaman, semakin awal tanaman terpapar suhu tinggi, semakin besar pengaruh negatifnya pada pertumbuhan (Rykaczewska, 2013).

\section{Jumlah Daun}

Tabel 3. Pengaruh Cekaman Suhu Tinggi pada Dua Varietas terhadap Jumlah Daun Table 3. Effect of High Temperature Stress on Two Potato Varieties to Leaf number

\begin{tabular}{lcc}
\hline & \multicolumn{2}{c}{$\begin{array}{c}\text { Jumlah Daun } \\
\text { Leafnumber }\end{array}$} \\
\cline { 2 - 3 } Perlakuan & $\begin{array}{c}\text { Atlantik } \\
\text { Atlantik }\end{array}$ & $\begin{array}{l}\text { Granola } \\
\text { Granola }\end{array}$ \\
\hline $\begin{array}{l}\text { Suhu } 32^{\circ} \mathrm{C} \\
\text { Temperature } 32^{\circ} \mathrm{C}\end{array}$ & $11,85 \mathrm{Bb}$ & $15,95 \mathrm{Aa}$ \\
Suhu $25^{\circ} \mathrm{C} / 35^{\circ} \mathrm{C}$ & $15,55 \mathrm{Aa}$ & $13,75 \mathrm{Aa}$ \\
Temperature $25^{\circ} \mathrm{C} / 35^{\circ} \mathrm{C}$ & $15,65 \mathrm{Aa}$ & $15,45 \mathrm{Aa}$ \\
Suhu $42^{\circ} \mathrm{C}$ & & \\
Temperature $42^{\circ} \mathrm{C}$ & & \\
\hline
\end{tabular}

Keterangan: huruf kecil (Vertikal) dan huruf kapital (Horisontal). Angka yang diikuti huruf yang berbeda menunjukkan perbedaan yang nyata menurut uji DMRT taraf $5 \%$.

Note: lowercase (vertical) and capital letters (horizontal). Numbers followed by different letters show asignificant difference according to the 5\% DMRT test.

Daun merupakan organ tanaman yang berperan dalam proses fotosintesis dan respirasi tanaman. Berdasarkan tabel 3 jumlah daun terbanyak pada perlakuan interaksi suhu kontrol dengan varietas granola kembang (T0V2) yaitu 15,95 helai. Jumlah daun tanaman ini erat kaitannya dengan tinggi tanaman. Varietas granola kembang memiliki nilai pertambahan tinggi tanaman yang lebih besar dibandingkan varietas atlantik sehingga berpengaruh terhadap jumlah daun yang lebih banyak jika dibandingkan varietas atlantik.

Daun pertama yang muncul merupakan daun tunggal dan pada pertumbuhan selanjutnya akan tumbuh daun majemuk, yang berfungsi sebagai proses fotosintesis (Sastrahidayat, 2011). Jenis varietas tetap konstan menunjukkan 
pengaruh terhadap jumlah daun tanaman kentang. Hal tersebut dapat terjadi karena adanya sifat-sifat yang berbeda pada tiap varietas yang mengatur setiap fase pertumbuhan tanaman. Selain itu suhu tinggi juga sangat mempengaruhi struktur anatomi, tidak hanya pada tingkat jaringan dan seluler, tetapi juga pada tingkat subseluler. Perubahan tersebut menyebabkan terhambatnya pertumbuhan tanaman. Selama stadia vegetatif, suhu siang hari yang tinggi akan merusak daun tempat pertukaran gas. Hal yang perlu menjadi perhatian yakni jumlah daun akan menjadi konstan ketika tanaman telah memasuki masa akhir fase vegetatif. Hal ini bertujuan untuk menyimpan energi tanaman untuk fase selanjutnya yakni fase generatif.

\section{Berat Umbi}

Tabel 4. Pengaruh Cekaman Suhu Tinggi pada Dua Varietas Kentang terhadap Berat Umbi (gram)

Table 4. Effect of High Temperature Stress on Two Potato Varieties to bulb weight (gram)

\begin{tabular}{lcc}
\hline & \multicolumn{2}{c}{$\begin{array}{c}\text { Berat Umbi } \\
\text { Bulb Weight }\end{array}$} \\
\cline { 2 - 3 } Treatment & $\begin{array}{l}\text { Atlantik } \\
\text { Atlantik }\end{array}$ & $\begin{array}{l}\text { Granola } \\
\text { Granola }\end{array}$ \\
\cline { 2 - 3 } $\begin{array}{l}\text { Suhu } 32^{\circ} \mathrm{C} \\
\text { Temperature } 32^{\circ} \mathrm{C}\end{array}$ & $10,6 \mathrm{Ba}$ & $6,03 \mathrm{Cb}$ \\
$\begin{array}{l}\text { Suhu } 25^{\circ} \mathrm{C} / 35^{\circ} \mathrm{C} \\
\text { Temperature } 25^{\circ} \mathrm{C} / 35^{\circ} \mathrm{C}\end{array}$ & $\mathbf{1 7 , 4} \mathrm{Aa}$ & $8,12 \mathrm{Bb}$ \\
$\begin{array}{l}\text { Suhu } 42^{\circ} \mathrm{C} \\
\text { Temperature } 42^{\circ} \mathrm{C}\end{array}$ & $5,7 \mathrm{Cb}$ & $10,02 \mathrm{Aa}$ \\
\hline
\end{tabular}

Keterangan: huruf kecil (Vertikal) dan huruf kapital (Horisontal). Angka yang diikuti huruf yang berbeda menunjukkan perbedaan yang nyata menurut uji DMRT taraf $5 \%$.

Note: lowercase (vertical) and capital letters (horizontal). Numbers followed by different letters show asignificant difference according to the 5\% DMRT test.

Tabel 4 di atas menjelaskan bobot umbi terberat ada pada perlakuan interaksi suhu $25^{\circ} \mathrm{C} / 35^{\circ} \mathrm{C}$ selama 15 hari dengan varietas atlantik (T1V1), kemungkinan hal ini dipengaruhi oleh faktor genetik dari varietas Atlantik yang memiliki struktur umbi lebih padat (sedikit kandungan airnya), dibandingkan varietas granola kembang. Bentuk umbi yang lebih padat menjadikan varietas atlantik sebagai komoditi untuk produksi keripik, bukan untuk sayuran. Perbedaan bobot umbi antar varietas di atas telah menunjukkan bahwa ada perbedaan genetik dalam varietas yang mengatur tanggap terhadap suhu ((Hamdani, 2009)). Dataran menengah memiliki kisaran suhu yang lebih tinggi dibandingkan dengan habitat aslinya di dataran tinggi. Suhu tertinggi di dataran medium saat cuaca cerah dapat mencapai $32^{\circ} \mathrm{C}$. Suhu yang terlampau tinggi untuk tanaman kentang dapat menaikkan respirasi tanaman serta menghambat pembentukan umbi. Hal inilah yang menyebabkan hasil umbi kentang di dataran menengah ini lebih rendah daripada di dataran tinggi. Fotosintat yang seharusnya ditimbun sebagai cadangan makanan berupa umbi, juga harus digunakan untuk proses respirasi tanaman akibat suhu tinggi sehingga berimbas pada pembentukan umbi yang tidak optimal. 


\section{Kandungan Karbohidrat}

Tabel 5. Pengaruh Cekaman Suhu Tinggi pada Dua Varietas Kentang terhadap Kandungan Karbohidrat (mg/g)

Table 5. Effect of High Temperature Stress on Two Potato Varieties to Carbohydrate Content $(\mathrm{mg} / \mathrm{g})$

\begin{tabular}{lcc}
\hline \multirow{2}{*}{$\begin{array}{l}\text { Perlakuan } \\
\text { Treatment }\end{array}$} & \multicolumn{2}{c}{$\begin{array}{c}\text { Kandungan Karbohidrat } \\
\text { Carbohydrate Content }\end{array}$} \\
\cline { 2 - 3 } & $\begin{array}{l}\text { Atlantik } \\
\text { Atlantik }\end{array}$ & $\begin{array}{c}\text { Granola } \\
\text { Granola }\end{array}$ \\
\hline $\begin{array}{l}\text { Suhu } 32^{\circ} \mathrm{C} \\
\text { Temperature } 32^{\circ} \mathrm{C}\end{array}$ & $7,03 \mathrm{Ab}$ & $22,49 \mathrm{Aa}$ \\
$\begin{array}{l}\text { Suhu } 25^{\circ} \mathrm{C} / 35^{\circ} \mathrm{C} \\
\text { Temperature } 25^{\circ} \mathrm{C} / 35^{\circ} \mathrm{C}\end{array}$ & $5,06 \mathrm{Bb}$ & $7,49 \mathrm{Ba}$ \\
$\begin{array}{l}\text { Suhu } 42^{\circ} \mathrm{C} \\
\text { Temperature } 42^{\circ} \mathrm{C}\end{array}$ & $6,20 \mathrm{Ab}$ & $7,017 \mathrm{Ba}$ \\
\hline
\end{tabular}

Keterangan: huruf kecil (Vertikal) dan huruf kapital (Horisontal). Angka yang diikuti huruf yang berbeda menunjukkan perbedaan yang nyata menurut uji DMRT taraf $5 \%$.

Note: lowercase (vertical) and capital letters (horizontal). Numbers followed by different letters show asignificant difference according to the 5\% DMRT test.

Kandungan karbohidrat yang menyusun dinding sel yang terdiri atas selulosa, pectin dan hemiselulosa dan polisakarida lain merupakan penguat antar sel pada umbi. Karbohidrat pada tanaman berupa reaksi $\mathrm{CO}^{2}$ dan $\mathrm{H}_{2} \mathrm{O}$ melalui proses fotosintesis pada sel tumbuhan yang mengandung klorofil (Sitompul \& Guritno, 1995).

Berdasarkan Tabel 5 menjelaskan bahwa perlakuan varietas menghasilkan hasil berbeda nyata terhadap variabel pengamatan kandungan kabohidrat. Perlakuan suhu V2 (Varietas Granola) menghasilkan nilai tertinggi $17,22 \mathrm{mg} / \mathrm{g}$ dibandingan dengan perlakuan suhu V1 (Varietas Atlantik) sebesar 4,57 mg/g.

Dari hasil percobaan didapatkan data bahwasannya perlakuan cekaman pada fase bibit berpengaruh nyata terhadap kandungan pati/amilum disemua varietas. Tersimpannya pati/amilum pada umbi sangat dipengaruhi oleh laju fotosintesis sebagai penghasil karbohidrat yang nantinya akan dirubah menjadi pati/amilum untuk ditranslokasi menuju akar dan membentuk umbi.

Laju fotosintesis sangat dipengaruhi oleh jumlah daun dan kondisi lingkungan. Ketika tanaman mendapatkan cekaman suhu tinggi, maka jumlah daun yang terbentuk akan sedikit dan cenderung lebih kecil dibandingkan tanaman normal. Hal ini sebagai respon tanaman untuk menekan laju transpirasi dan fotorespirasi ketika berada dalam cekaman suhu tinggi. secara tidak langsung hal ini akan berpengaruh pada laju fotosintesis. Suhu tinggi akan menutup stomata, sehingga akan menurunkan laju fotosintesis. Laju fotosintesis yang rendah akan berdampak pada hasil fotosintat yang rendah pula. Apabila tanaman mengalami cekaman suhu tinggi dalam jangka panjang, maka hasil fotosintat ini akan lebih banyak digunakan untuk perbaikan sel-sel dan jaringan organ vegetatif. Kondisi ini akan menghambat inisiasi pembentukan umbi, sehingga umbi yang dihasilkan sedikit dan relatif memiliki berat yang ringan. 
Pada granola kembang mampu memberikan hasil kandungan pati/amilum lebih besar. Hal ini dapat disebabkan karena dari organ vegetatifnya lebih baik. Seperti tinggi tanaman yg lebih tinggi, dan jumlah daun yg lebih banyak, sehingga hasil fotosintat nya lebih banyak dibandingkan atlantik. Tetapi, jika melihat kebutuhan pemanfaatan tanaman maka seharusnya yang memiliki pati lebih tinggi adalah varietas atlantik. Karena varietas atlantik ini kurang mampu bertahan dalam kndisi cekaman suhu, maka kandungan pati/amilumnya lebih rendah.

\section{KESIMPULAN}

Hasil penelitian interaksi antara perlakuan cekaman suhu kontrol $32^{\circ} \mathrm{C}$ dan varietas granola kembang menunjukkan hasil terbaik pada variabel pengamatan tinggi tanaman sebesar $36,31 \mathrm{~cm}$, jumlah daun sebanyak 15,95 helai, dan kandungan karbohidrat sebesar 22,49 $\mathrm{mg} / \mathrm{g}$. Sedangkan interaksi antara perlakuan cekaman suhu kontrol $32^{\circ} \mathrm{C}$ dan varietas atlantik menunjukkan hasil terbaik pada variabel pengamatan berat umbi sebesar 17,4 gram.

\section{DAFTAR PUSTAKA}

Asgar, A. (2013). Umbi Kentang (Solanum tuberosum L.) Medium Mempunyai Harapan untuk Keripik. Iptek Holtikultura, 2(9), 32-35.

Badan Pusat Statistik. (2017). Luas Panen, 锿 Produksi, dan Produktivitas Kentang. Retrieved from https://www.bps.go.id/subject/55/ho rtikultura.html

Diny, D., Handayani, T., \& Sofiari, E. 信 (2017). Toleransi Tanaman Kentang (Solanum tuberosum) terhadap Suhu Tinggi Berdasarkan Kemampuan Berproduksi di Dataran Medium [ Heat Stress Potato (Solanum tuberosum) Tolerance Based on Tuber Production in Medium Altitude ]. J. Hortikultura, 27(1), 110. https://doi.org/10.21082/jhort. v27n1.2017.p1-10

Enoch, G. J., Lengkong, E. F., Pongoh, J., 顽 Pertanian, M. F., Ratulangi, U. S., Pertanian, J. B., \& Pertanian, F. (2018). Pengaruh Pengunaan Mulsa pada Pertumbuhan dan Produksi Tanaman Kentang (Solanum tuberosum L.) di Dataran Menengah. Cocos, 1(1), 1-10.

Hamdani, J. S. (2009). Pengaruh jenis mulsa terhadap pertumbuhan dan hasil tiga kultivar kentang (Solanum tuberosum L.) yang ditanam di dataran medium. Jurnal Agronomi Indonesia, 37(1).

Kusmana, N. (2012). Seleksi Beberapa Klon Kentang (Solanum tuberosum L.) dari Hasil Persilangan untuk Karakter Daya Hasil Tinggi pada Ekosistem Dataran Tinggi di Ciwidey. Buletin Plasma Nutfah, 18(2), 45. https://doi.org/10.21082/ blpn.v18n2.2012.p45-53

Pusat Data dan Informasi. (2016). Konsumsi Per Kapita Rumah Tangga Setahun menurut Hasil Survei Sosial Ekonomi Nasional. Retrieved from https://aplikasi2.pertanian.go.id/kon sumsi/tampil_susenas_kom2_th.php

Rykaczewska, K. (2013). The Impact of E High Temperature During Growing Season on Potato Cultivars with Different Response to Environmental Stresses. American Journal of Plant Sciences, 04(12), 2386-2393. https://doi.org/10.4236/ ajps.2013.412295 
Sadasivam, A., \& Manickam. (2017).

钢 Analisis Kuantitatif Kandungan Total Karbohidrat Dalam Sampel Tepung Dengan Pereaksi Anthrone Secara Spektrofotometri, 4-9.

Sastrahidayat, I. R. (2011). Tanaman 镐 Kentang dan Pegendalian Hama Penyakitnya. Malang: Universitas Brawijaya Press.

Sitompul, S. M., \& Guritno, B. (1995).

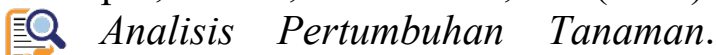
Yogyakarta: UGM press.

Syahbudin; Yuwariah, Y; Hamdani, J. S. 琶 (2013). Peningkatan Kualitas Hasil Ubi Tiga Varietas Kentang melalui Aplikasi Paklobutrazol di Dua Dataran Medium. JAS, 3. 